Reinders, H. \& Lázaro, N. 2008 'The assessment of self-access language learning: practical challenges. ' Language Learning Journal, 36(1), 55-64.

\title{
THE ASSESSMENT OF SELF-ACCESS LANGUAGE LEARNING: PRACTICAL CHALLENGES ${ }^{1}$
}

\author{
Hayo Reinders \& Noemí Lázaro \\ University of Auckland, New Zealand \\ Universidad Nacional de Educación a Distancia, Spain
}

\begin{abstract}
Self-access centres are a popular type of language support offered by an increasing number of schools and universities around the world. Assessment of the learning that takes place in such Centres is seen as both crucial and problematic. There appear to exist many barriers to successful assessment but these have not been comprehensively documented, making it difficult to develop systematic solutions. This article presents the results of a study of 46 self-access centres in five countries (Germany, Hong Kong, Spain, Switzerland, and New Zealand), investigating current assessment practice. In-depth strength-weakness analyses were conducted with the managers of each of the participating Centres. These revealed a complex interaction between pedagogical and practical challenges to assessment. They also showed an emphasis on the developmental role of assessment for learner autonomy and the importance of assessing both language gains and learning skills.
\end{abstract}

Keywords: assessment, learner autonomy, self-access centres.

\section{Introduction}

\footnotetext{
${ }^{1}$ This study has been conducted in part with funding from the Consejería de Educación de la Comunidad de Madrid, the European Social Fund, the DAAD (German Academic Exchange Service) and the "La Caixa" Foundation.
} 
A strong rationale has been given in the literature for the development of self-access language learning centres over the years (Esch 1994; Gardner \& Miller 1999). Despite anecdotal evidence for their success, calls are increasingly made by stakeholders such as funding bodies and department heads, as well as students, parents and teachers, for self-access to show that it offers a time-, and cost-effective approach to learning a second language, or that it has additional benefits to learning not offered by other types of learning environments. In practice, no comparative studies have been done that the authors are aware of, that looked at the relative effects of self-access versus other types of learning. One area in which progress has been made, however, is in developing approaches to assessment of individual students' learning in the selfaccess context (see Reinders \& Lázaro 2007). This could be used as one starting point for evaluating the contribution of self-access centres to student learning. However, it is clear that the topic of assessment in self-access is a contentious and problematic one. There are considerable challenges in investigating learning gains in an environment where variables cannot be comprehensively controlled for. This article is an attempt to identify what those challenges are in practice and what solutions have been found in 46 self-access centres in five countries. The results can be used to inform other practitioners and help develop new approaches to assessing self-access language learning.

\section{Literature review}

Several authors have pointed out the need for the field of self-access to concern itself more with assessment (Gardner \& Miller 1999, Morrison 1999, 2006, Lázaro \& Reinders 2007, see also a recent issue of System, 2007). Despite these calls, little research to date has been conducted on the contributions self-access learning makes to language learners' development and on ways in which such progress could be measured. Partly, this is due to difficulties in assessing self-access language learning (see below) and a lack of published guidelines or instruments. A series of case studies conducted by the Centre for Independent Learning (CIEL 2003) found a wide range of assessment types, including the use of learning portfolios, group or one-to-one discussions of learning progress, portfolio-based examination questions (where questions in exams refer back to 
the learners' portfolios), peer-assessment and self-assessment, and oral presentations based on independent learning. The study recommended that in addition to language gains, also learning skills be investigated. This could be done by, amongst others, looking at students' self-awareness, their ability to analyse their needs, work in groups, use learning strategies, self-motivate, monitor progress, peer,- and self-assess, the ability to plan their learning, and select appropriate resources. However, the case studies also show that these assessment measures are not implemented in a systematic way and the measures used are generally not validated in any way.

One defining aspect of self-access centres is their focus on developing learner autonomy, or 'the ability to take responsibility for one's own learning' (Holec 1981). Measures of autonomy could thus potentially be of use to self-access practitioners. However, no such generally accepted measures exist. In the words of Sinclair (1999, p. 106-107): "It is apparent that learner autonomy is not an easily-described single behaviour. Furthermore, there are so many variables that affect a learner's degree of autonomy at any one time that it is clearly impossible to evaluate autonomy based on observable behaviour." She proposes various approaches to assessing learner autonomy: a) through gains in language proficiency, although she points out there is little evidence that programmes that aim to foster autonomy lead to greater language proficiency (but see Dam \& Legenhausen 1996), b) by investigating students' attitudes and motivation, although this has the problem that changes do not "necessarily demonstrate that students have become more effective and independent learners as a result (p.98). c) by logging student activity to find evidence for students' increasing autonomy, and finally, d) through experiments in strategy training, which although sometimes inconclusive, tend to evidence "the trainability of language learning strategies and their effect on learning success and autonomy" (p.99). Although these are important elements for assessing learner autonomy, Sinclair proposes to further assess autonomy as a 'construct of capacity' (p.101), that can be analysed though the students' metacognitive awareness. A set of criteria for assessing metacognitive awareness are proposed, in the following terms:

"Can the student: 
- provide a rationale for his/her choice of learning activities and materials?

- Describe the strategies he/she used?

- Provide an evaluation of the strategies used?

- Identify his/her strengths and weaknesses?

- Describe his/her plans for learning?

- Describe alternative strategies that he/she could have used?"

(Sinclair, 1999:103)

This list, to some extent, overlaps with that offered by CIEL. It allows teachers/researchers to classify learners as largely unaware, becoming aware, and largely aware. To the best of our knowledge, however, such measures have not been implemented or tested systematically.

One practical implementation of the ideas suggested above is offered by Ravindran (2000, 61-62) who describes the Certificate in Independent Language Learning at the Centre for Individual Language Learning (CILL) at Temasek Polytechnic, Singapore. This certificate recognises students' independent learning skills through a set of criteria, based on Knowles's (1975) key skills of self-directed learning, Rubin's (1998) monitoring skills, and Wenden's (1995) task appraisal skills. Students are considered to be independent learners when they are (amongst others) able to work with peers, diagnose their own learning needs, monitor and evaluate learning progress. In order to successfully complete the course, students need to show a certain level of awareness and understanding of these skills, and have to apply them in practice while working through the Certificate programme. To assess this, a range of measures is obtained throughout the course of students' levels of awareness and display of independent learning skills, students' self-assessments, learner diaries, the quality of their reflections, etc. Like others, Ravindran reported difficulties in establishing uniform benchmarks and issues around obtaining inter,- and intra-rater reliability.

Regardless of their drawbacks, attempts such as those presented above offer important suggestions for investigating independent learning. However, as far as we are aware, such lists 
and frameworks have not been applied in practice in a self-access setting. Some unique features of self-access centres (compared with, for example, the classroom environment in Ravindran's certificate course) contribute to this lack of application. Gardner (1999) identifies five main obstacles: 1) the complexity of self-access systems (due to the individualised learning they support), 2) their uniqueness (little research has been done, making new research challenging), 3) difficulties of data collection (as there is less control than in a classroom situation over what learners do and when), 4) difficulties of data analysis (because often less is known about the learners who may use the centre voluntarily and infrequently), 5) the purposes of evaluation (which are generally focused on resource management). In addition to these a major (perhaps the main) difficulty stems from the fact that a learner's progress can almost never be attributed solely to self-access learning. Self-access centres are by definition open, flexible environments and learners select their own pathways, materials, and set their own goals. In addition to the work they do within the centre they may work on their own, be enrolled in courses, take private lessons or practise with other learners. Even if these variables could be comprehensively controlled for, learners who choose self-access may be dissimilar from those who do not in terms of their motivation, their predisposition to self-directed learning, and perhaps their pre-existing level of autonomy and/or metacognitive awareness.

This study aims to further investigate what obstacles, both methodological and practical, exist to assessment in self-access. It builds on an earlier study by the authors that looked into current assessment practice in 46 self-access centres worldwide (Reinders \& Lázaro 2007). In this study, the authors found that $52 \%$ of all centres did not conduct any type of assessment whatsoever. In the centres that did carry out assessment, self-assessment and collaborative assessment with a language advisor were the most popular forms.

Table 1: Types of assessment in SAC

\begin{tabular}{|l|c|c|c|}
\hline Type of assessment & $\mathbf{n}=\mathbf{4 6}$ & $\%$ & $\begin{array}{c}\text { \% of assessment } \\
\text { measures }(\mathbf{n}=22)\end{array}$ \\
\hline No assessment & 24 & 52 & \\
\hline
\end{tabular}




\begin{tabular}{|l|c|c|c|}
\hline Self-assessment & 18 & 39 & 82 \\
\hline Collaborative assessment with advisor & 13 & 28 & 59 \\
\hline External examination/ test & 9 & 20 & 41 \\
\hline Teacher assessment & 7 & 15 & 32 \\
\hline Advisor assessment & 4 & 9 & 18 \\
\hline Peer evaluation & 4 & 8 & 18 \\
\hline Panel & 1 & 2 & 5 \\
\hline
\end{tabular}

\section{The study}

This study investigated issues relating to assessment practice in 46 self-access centres in five countries (Germany, Hong Kong, New Zealand, Spain and Switzerland). As part of the study each centre was visited and extensive interviews were conducted with their managers. During each interview a SWOT analysis (strengths, weaknesses, opportunities and threats) was conducted of the centre. As part of the interviews extensive discussion took place on the topic of assessment in the centre, especially on current assessment practice and the strengths and weaknesses of the procedures in place in the Centre (no questions were asked about opportunitie and threats relating to assessment, although participants did bring these up). This was coupled with observations made by the researchers in the centres of the range of available assessment practices. The interviews were recorded and subsequently analysed to identify issues faced by management and staff in developing and implementing the assessment measures through a categorical content analyses (see Bardin 1983, L’Ecuyer 1990).

\section{Results}

Below the results of the SWOT analysis are reported. It is important to point out that although the number of responses reported here is only 22 , the actual number of participants was 46 . However, 24 centres did not conduct any type of assessment so were not interviewed on this topic.

\section{Strengths}

The categories below show the strengths as reported by the SAC practitioners who were interviewed during the study. 


\section{Encouraging reflection (4/22)}

The most commonly mentioned strength of the assessment process in the SACs visited is the opportunity that this process offers the students to reflect on their own learning. Encouraging reflection is a key aspect of increasing learners' autonomous learning skills, as identified in the literature (e.g. Wenden 1991), and as mentioned by the interviewees. Through reflecting on the learning process and their progress, learners can more consciously make decisions about their own learning. As such, it is not surprising that this is the most commonly agreed on purpose for assessment in a self-access setting. In the words of one of the participants: 'It's the idea that this can serve as a way to encourage constant reflection on the part of the learners so they can make informed decisions - that is what we try to achieve'.

The use of alternative assessment (4/22)

In self-access alternative forms of assessment to those commonly found in classroom settings are used relatively frequently. This includes assessment conducted by learners themselves, through self- or peer-assessment. It also includes assessment of progress other than that measured through learning gains, such as autonomous learning skills, and the use of alternative tools such as portfolios, learner diaries etc. This was seen as a strength by several of the participants: 'If we wan to encourage other, new ways of learning and teaching, then surely we need to find new ways of assessing that learning. The freedom we have in a self-access environment from standardised testing lets us experiment'.

\section{Assessments are conducted (3/22)}

At first glance this may sound too obvious to have been mentioned in the interviews. However, this should be seen in the light of the earlier reported results that showed that only $48 \%$ of the 46 SAC investigated conducted any type of assessment at all.

Gives a central role to the learner (2/22) 
In the autonomous learning process, the learners necessarily have a central role. This central role necessitates a change in the traditional teacher and learner roles. One way of doing this is by giving students control over their own assessment, for example through self-assessment: 'The strength of self-assessment is that it continuously helps the students to remain aware of themselves as learners.'

Is individualised (2/22)

Assessment in self-access is often individualised as in many cases learners use the SAC independently and each learner works with a unique set of resources and with a personalised learning plan. This necessarily makes the assessment relevant to the learner, which fits in well with the learner-centred approach of self-access centres. One of the managers highlights the importance of establishing personal links with the students as part of the assessment process:

'Assessment is obviously more personalised in these programmes, more collaborative in these processes, because collaborative assessment is working every time counsellor and students meet. And this is very rich, this is really very rich. Specially doing what in traditional settings would not be possible, asking the student, apart from assessing the process: How do you feel/are you feeling in this process?'

\section{Voluntariness (2/22)}

The learner-centred aspect of self-access is reflected in the positive perception by managers of assessment as a voluntary activity. As an alternative to compulsory assessments (both in classroom-based language classes and in wider curriculum) that are prevalent in most of the institutions visited as part of this study, the voluntary nature of assessment in self-access centres is seen by managers to have a positive effect on motivation. The decision to undergo assessment or to self-assess is made by the learner and it is thus more likely to be motivated by an internal desire to obtain genuine feedback on progress. The downside, of course, is that some students choose not to be assessed at all. As one of the managers explains 'You need to bear in mind that 
most people working in a SAC do so in 'extra time' and find it hard to consider any aspect of their learning process other than the learning itself'.

Assessment as a way of monitoring progress (2/22)

Another strength of the assessments conducted in the SAC is the possibility offered to the students of monitoring their own learning process. Although this is the case with many types of assessments, in the self-access context where assessment is not common, this is seen as a distinct advantage. 'The idea is to engage the student in his own learning process, so that he doesn't always need to depend on others to assess.'

Others (mentioned only once each)

Other strengths mentioned only once include that assessment is offered in a balanced way (not too often), that it allows follow-up to take place, that it is done continuously, that it leads to integration with existing language courses, provides guidance and feedback, and that it is done in a reliable manner.

\section{Weaknesses}

The next section reports the weaknesses of the assessment carried out in the centres, as reported by the managers.

Lack of systematic assessment (6/22)

The most commonly perceived weakness of assessment in the SAC context is that it is usually informal and not very systematic. Respondents commented on the lack of well defined criteria and the lack of consistent implementation. The assessment process is generally not integrated into the learning process, so that students do not see the relation between what they do and what they are supposed to assess. In the words of one manager (translated from Spanish by the 
authors): 'We have to improve our assessment procedures. I think we have quite a good procedure but it's not enough. We have to work out a comprehensive approach to assessment'.

As one of the interviewed managers explains through a culinary metaphor, the assessment is the closing piece of a process that needs to be well structured: 'When you prepare a meal, the dessert is the least important. First you need to know how many people there will be, prepare tables and chairs, select a good wine, find the best ingredients, decide on your dishes...that is to say, the dessert is important, but it is important at the end'.

\section{Lack of reliability (4/22)}

Four respondents pointed out the lack of reliability of assessment in self-access, as there is no 'objective' assessment available to them. One manager explains: 'They are potentially useful, but at the same time it just masquerades the huge weakness, which is the fact that there is no way to actually assess the students, and the students do want some sort of what they perceive to be an objective validation of their work. Especially students from Asian countries that are very performance driven, very test driven. Students just want to put a figure, a score to their language learning.'

Time consuming (4/22)

Assessment in self-access is time consuming. This is a result of the individualised nature of selfaccess whereby group assessments are generally impossible and each learner may focus on a different language aspect. In addition, the alternative types of assessment common in SACs are in themselves particularly time consuming: 'Frequent use of such tools [i.e. alternative forms of assessment] ends up requiring so much energy, that you wouldn't have time for anything else. That's why I think that we have to improve the processes and systematise the data gathering, so that afterwards we can better manage them and interpret them.'

Students' reluctance to alternative forms of assessment (4/22) 
In many SACs assessment is voluntary but this option is not often used by students. Selfassessment through worksheets or logbooks is offered in many centres but students may not feel confident to assess themselves or may not see the value of an assessment that is not done by a teacher. Says one manager: 'A lot of students do not really consider their peers as a source of information, as a source for feedback. A lot of people think that they themselves are not really good judges when it comes to language.' A potential problem with electronic portfolios is their lack of acceptance by teachers, students and future employers.

Some SACs report that their students are very exam-focused and want to see clear 'pre- and 'post-' scores. Although some report considering such tests, the lack of commercially available resources is a problem.

Students lack the skills for self- and collaborative assessment (2/22)

Many students have little experience in assessments that are not teacher-led and without proper training may not benefit from it. In the words of one manager: 'Sometimes students do not achieve the level of reflection that we would like. Many times students may try to, but are not able to assess themselves, that's why external assessment is still very important for them. This is one of the aspects of learner autonomy that is most difficult to develop. You may try to encourage it, but you realise that there are certain limitations.'

\section{Others (mentioned only once each)}

Other weaknesses mentioned included that it can take place without a proper, supportive context: 'The weakness of assessment, is that if it is not provided within a proper context it can be very demotivating. Especially for Pacific Island students. They have enough failing in their lives. So they don't want to really be told that they are failing again.' Another SAC manager mentioned that they had been obliged by the institution to carry out assessments in the form of tests but that this goes against the principles of self-access adhered to in that context: 'The weak point is that these tests go against the philosophy of the system. We first treat students as individuals but then lump 
them all together for the test. It is not consistent.' Others mentioned the fact that oral skills are not assessed and that there is no adequate training for SAC staff to carry out assessments.

\section{Discussion}

As reported at the start of this article, the majority of SACs (24 out of 46 centres) do not carry out any type of assessment. The results reported above reveal some of the likely reasons for this. The first of these is methodological: there are serious challenges related to the lack of reliability of assessment measures. As mentioned earlier, it is almost impossible to isolate the contribution self-access makes to learning gains and in such an open learning environment there are simply too many learner differences to be controlled and accounted for. The open nature of self-access also results in a lack of systematicity in the centres' approaches to assessment. Some learners may be required to use the centre as part of their language courses and may be assessed by their teachers over a longer period of time. Others may join activities in the centre (e.g. workshops, group-work) that include some form of immediate assessment whereas yet others may come in occasionally and never be assessed.

Other issues are institutional in nature. Participants confirmed findings from earlier studies that showed that self-access does not always enjoy strong institutional support (cf. Reinders et al. 2003) and this extended into the area of assessment. Developing appropriate assessment procedures and instruments is challenging, especially in an area where not much work has yet been done. Also, assessment of self-access learning is quite time-consuming (especially in the area of oral skills). Lack of financial support and training were found to be additional impediments.

Learner and staff attitudes form a final challenging category. Interviewees reported some reluctance on the part of learners to learn independently and to have that learning assessed. Alternative forms of assessment, especially those that do not involve a teacher, such as peer,- or 
self-assessment, may not be perceived to be helpful, either by teachers or learners. Better preparation and ongoing support appear to be needed.

At the same time there are also a number of strengths that are reported by the participants. Looking closely at the responses above it is clear that most of the benefits of assessment seen by the managers relate to the opportunities it offers for the development of learner autonomy. Assessment is seen to 'encourage reflection', gives a 'central role to the learner', is 'voluntary', and 'individualised'; all features of autonomous learning. There appears to be less emphasis on some other potential benefits that are often mentioned in more traditional settings such as 'accountability' (of learners, teachers and managers). In other words, assessment in self-access is largely seen as a learner-centred activity, and not so much an institution-centred activity. Its purpose differs from that normally found in language teaching contexts. This may have both benefits and drawbacks.

Of course there are limitations to what a study based on managers' perceptions can hope to achieve. Different managers may understand the questions differently or may want to give a better image of their centre. This was attempted to be overcome by emphasising the anonymous nature of the study and by asking probing questions when answers appear to be vague or did not match the researchers' observations. For the purposes of the content analyses, the two researchers made separate analyses of the participants' answers and resolved ambiguous cases through discussion. Nonetheless, analysis of managers' responses alone, even if coupled with observations, only give one perspective. Future studies could look more closely at learners' experiences with and expectations of assessment in self-access learning or could investigate in detail how different types of assessment are carried out in practice, in order to document their strengths and weaknesses.

\section{Conclusion}


The results show that assessment in self-access is seen as a learner-centred activity. In an environment where learners, to a large extent, determine their own learning paths, this seems appropriate; assessment would need to take into account the individual nature of each learner's work. In addition, assessment in self-access focuses on both language gains and on improvement in the ability to learn independently. Both of these features (individualisation and independent learning skills) make assessment particularly demanding. To some extent this may be overcome by efforts to systematise assessment and to develop more reliable measures for this type of learning context. The development of clear criteria could be a helpful starting point and can draw on existing work, reviewed above. However, a greater degree of institutional support, especially time and training, will be necessary for this. Also, learners need to be provided with a rationale for assessment in self-access centres and preparation and training in the types of (alternative) assessment they will encounter in them. On-going support is also key; a learner who is asked to self-assess will likely need some sort of validation, at least initially, before developing the confidence to rely on that assessment. Teachers will likely also need adequate training. Although self-access centres aim to encourage increased learner responsibility, this does not mean that our responsibilities as teachers, researchers and language testers diminish.

\section{References}

Bardin, L. (1983) L'analyse de contenu des documents et des communications, Paris, PUF.

Centre for Independent Learning (2003) Assessment and independent language learning. Available from: http://www.llas.ac.uk/resources/goodpractice.aspx?resourceid=1407, last retrieved March 28, 2007.

Dam, L., \& Legenhausen, L. (1996) The acquisition of vocabulary in an autonomous learning environment- the first months of beginning English. In Pemberton, R. et al. (Eds.) Taking control: Autonomy in language learning , Hong Kong, Hong Kong University Press, 93- 
Esch, E. (1994) Self-Access and the Adult Language Learner, London, CILT.

Gardner, D. (1999) The evaluation of self-access centres. In Morrison, B. (Ed.) Experiments and Evaluation in Self-access Language Learning. Selected papers from the 2nd HASALD conference, 5th September, 1998, Hong Kong, HASALD, 111-122.

Gardner, D. \& Miller, L. (1999) Establishing Self-Access, Cambridge, University Press.

Holec, H. (1981) Autonomy and Foreign Language Learning, Oxford, Pergamon.

Knowles, M. (1975) Self-Directed Learning: a Guide for Learners and Teachers, New York, Cambridge, the Adult Education Company.

L'Ecuyer, R. (1990) Méthodologie de l'analyse développementale de contenu, Québec, Presses de l'université du Québec.

Lázaro, N., \& Reinders, H. (2007) Innovation in self-access: Three case studies. CALL-EJ, 8 (2).

Morrison, B. (1999) Experiments and Evaluation in Self-access Language Learning, Selected papers from the 2nd HASALD conference, 5th September, 1998, Hong Kong, HASALD.

Ravindran, R. (2000) Towards Learner Autonomy: Evolution in Practice- the Certificate in Independent Language Learning. In Sinclair, B., McGrath, I. \& Terry L. (Eds.) Learner Autonomy: Future Directions, London, Longmann, 60-71.

Reinders, H., Anderson, H. \& Jones-Parry, J. (2003) Self-access language learning in tertiary 
studies in Australia and New Zealand: a preliminary report. New Zealand Studies in Applied Linguistics 9 (1), 109-114.

Reinders, H. \& Lázaro, N. (2007) Current approaches to assessment in self-access language learning. Manuscript submitted for publication.

Rubin, J. (1998) 'Monitoring': on-line discussion on monitoring skills". AutoL discussion, OctoberNovember 1998. AUTO-L@ycvax.york.cuny.edu

Sinclair, B. (1999) Wrestling with a jelly: the evaluation of learner autonomy. In Morrison, B. (Ed.) Experiments and Evaluation in Self-access Language Learning. Selected papers from the 2nd HASALD conference, 5th September, 1998, Hong Kong, HASALD, 95-109.

Wenden, A. (1995) Learner Training in Context: A Knowledge-Based Approach. System, 23 (2), 183-94.

Wenden, A. (1991) Learner Strategies for Learner Autonomy, New York, Prentice Hall. 